\title{
Wavelet characterisation of eucalypt flowering and the influence of climate and budding
}

\author{
$\underline{\text { I.L. Hudson }}^{\text {a }}$, I. Kang ${ }^{\mathrm{b}}$ and M.R. Keatley ${ }^{\mathrm{c}}$ \\ ${ }^{a}$ School of Mathematical and Physical Sciences, The University of Newcastle, New South Wales, \\ ${ }^{b}$ Statistics New Zealand, Christchurch, New Zealand, ${ }^{c}$ School of Ecosystem and Forest Sciences, The \\ University of Melbourne, Creswick, Victoria \\ Email: irene.hudson@newcastle.edu.au; irenelena.hudson@gmail.com
}

\begin{abstract}
In this study we examine the influence of climate (temperature and rainfall) on both flowering and budding, of E. leucoxylon and E. tricarpa from Victorian Forest Commission records and the field diaries of the Forest Overseer from Maryborough, Victoria between 1940 and 1962. Observations on the timing, quantity and distribution of flowering and budding of these species were collected on a monthly basis and placed into categories which had been pre-determined by the Commission. Flowering and budding intensity of both species were quantified by assigning a rank value producing a categorical time series (Table 1).
\end{abstract}

Table 1. Terms for budding and flowering intensity and assigned value.

\begin{tabular}{|l|l|l|c|c|}
\hline \multirow{2}{*}{$\begin{array}{l}\text { Observation } \\
\text { parameter }\end{array}$} & \multirow{2}{*}{ Symbol } & \multicolumn{1}{|c|}{ Description } & \multicolumn{2}{|c|}{ Value } \\
\cline { 3 - 5 } & & & Buds & \multirow{2}{*}{ Flowers } \\
\hline & & & & \\
\hline & $\mathrm{X}$ & No buds/No flowering & 0 & 0 \\
\hline & & Very scattered or isolated* & 0.5 & 0.5 \\
\hline & $\mathrm{L}$ & Light Crop/Flowering & 1 & 1 \\
\hline & $\mathrm{M}$ & Medium Crop/Flowering & 2 & 2 \\
\hline & $\mathrm{H}$ & Heavy Crop/Flowering & 3 & 3 \\
\hline & 1 & Small (recently formed) & 1 & N/A \\
\hline & 2 & Medium & 2 & N/A \\
\hline Distribution & 3 & Mature (ready to flower) & 3 & N/A \\
\hline & & Isolated* & 0.5 & 0.5 \\
\hline & $\mathrm{S}$ & Scattered & 1 & 1 \\
\hline & & Fairly General* & 1.5 & 1.5 \\
\hline
\end{tabular}

Eucalyptus leucoxylon and E. tricarpa both had significant negative relationships at 2 and 4 months with all temperature variants (minimum, maximum and mean temperature). Eucalyptus tricarpa was the only species for which rainfall had a significant, positive relationship with flowering at the 4 month scale. For E. leucoxylon the highest absolute value of wavelet correlation occurred between flowering and minimum temperature and for E. tricarpa with maximum temperature significant at the 4 month scale. Level 4 profiles indicate a two year cycle in bud and flowering production.

Significant wavelet cross-correlational (WCCORRs) relationships ( $\mathrm{P} \leq 0.0001)$ were found only between flowering and budding for rainfall at 4 months (wavelet scale, level 3) and at 2, 4 and 8 months (levels 2, 3 and 4) for the temperature variants. WCCORRs reveal seasonal dynamics and lead/lag relationships of climate on both flowering and on budding. For E. leucoxylon peak budding based on imputed values aligns with the start month of flowering and occurs 3 to 4 months prior to peak flowering. For E. tricarpa budding reaches a peak the month prior to the commencement of flowering and 3 months prior to peak flowering. Wavelet crosscorrelations (WCCORRs) established the cyclical influence of climate on both peak flowering and budding; and of budding on flowering.

For each species there are on average 6 months of the annual cycle in which minimum temperature and rainfall positively influence flowering and budding intensity and also 6 months of negative influence. The WCCORRs demonstrate that for both species temperature and rainfall do not act in concert on flowering nor on budding. Our results indicate temperature may be influencing bud development, not so rainfall, where temperature in turn influences flowering; also impacted by rain. This complex interplay between climate and budding on flowering needs further work with the examination of additional species, but, given that flowering is dependent on budding, our postulate makes sense.

Keywords: Wavelets, Eucalypt flowering, budding, phenophases, Wavelet (cross) correlations 


\section{INTRODUCTION}

To further our understanding of the influence of climate on say, flowering, it is important to understand the influence of previous phenological stages and the interaction between them as the timing of each phenophase is influenced by the previous (e.g. bud development rate influences the timing and quantity of flowering) (Keatley and Hudson, 1998; Post et al., 2008; Primack, 1987). In eucalypts, the development of buds often commences in a different season or, if in the same season, it can occur in different years (Dooley et al., 2010; Law et al., 2000; Murray and Lutze, 2004). Climate influences on budding may therefore be different to influences on flowering. The impact of climate on eucalypt budding has rarely been examined to date (Porter, 1978; Semple and Koen, 2010). Recently Hudson and Keatley (2013) studied the influence of climate on budding, along with the effects of budding on flowering, as well as the interaction of current climate and current and past budding on flowering, via Generalised Additive Models for Location, Scale and Shape (GAMLSS) (Hudson et al., 2010, 2011b). In this present study we use wavelets to uncover the bivariate current and lagged cross-correlational status of climate on budding, of budding on flowering, and of climate on flowering. This work extends wavelets models to two phenophases in relation to climate of our species (Hudson et al., 2010).

\section{METHODS}

\subsection{Phenological and climate data}

Records of budding and flowering of two eucalypt species (Eucalyptus leucoxylon and E. tricarpa) from the the field diaries of the Forest Overseer from Maryborough, Victoria between 1940 and 1962 were used in this study. Entries only cover this period. Observations on timing, quantity and distribution of flowering and budding of these species were collected on a monthly basis and placed into categories which had been predetermined by the Victorian Forest Commission. Flowering. Budding intensity of both species was quantified by assigning a rank value producing also a categorical time series (Table 1). Methods for defining flowering and budding behaviour (start, peak, finish and monthly intensity) are given in Hudson and Keatley (2013). Missing budding data was imputed using 'mi' in R (Su et al., 2011). Monthly minimum (MinT), maximum temperature (MaxT) and rainfall for the period 1936-1962 were provided by the Bureau of Meteorology. Monthly mean temperature was calculated from minimum and maximum temperatures. All temperatures are in Celsius.

\subsection{Analytic methods}

To analyse the flowering and budding profiles we used the discrete wavelet transform (DWT) and the maximal overlap DWT (MODWT) whereby the original time series, were constructed as an additive decomposition, known as a multiresolution analysis (MRA) (Gencay et al., 2001). Wavelet correlations and cross-correlations between both peak flowering intensity and budding, and with respect to the temperature variants and rainfall at different wavelet scales (1, 2, 4, 8, 16 and 32 months) were also examined. The DWT applied here, required a discretisation of the continuous time series variable, $Y_{t}$ to analyse and recover signals over a discrete set of scales, sampled at dyadic sequences $\left(\lambda_{j}=2^{j-1}, j=1,2,3, \ldots\right)$. The MODWT, a non-decimated variation of the DWT gave $N$ wavelet coefficients for each scale (Whitcher et al., 2000). These scale MODWT coefficients were then used to examine the wavelet correlation and wavelet cross-correlation of the following sets of bivariate time series - budding with climate, flowering with budding, and flowering with climate. The wavelet cross-correlation provided the lead or lag relationship on a scale-by-scale basis, similar to conventional crosscorrelations, which determine lead/lag relationships of two time series. Lags up to 36 months were used. DWT and MODWT-MRA were obtained by the methods of Percival and Walden, (2000) and of Gencay et al., (2001).

\section{RESULTS}

\subsection{Climate influences on budding}

The wavelet correlation between peak budding intensity and temperature variants (minimum (MinT) and maximum (MaxT)) at different wavelet levels or scales (1, 2, 4, 8, 16 and 32 months) were examined (Figure 1). Significant $(\mathrm{P}<0.05)$ wavelet correlations are those, where the upper $(\mathrm{U})$ and lower $(\mathrm{L})$ confidence limits are on the same side of the zero line. It can be seen that correlations at scale 2 and 3 ( 2 and $2^{3-1}=4$ months) are significant (Figure 1). Budding is not significantly influenced by rainfall (Table 2). From Table 2 an inverse relationship between budding and both temperature variants is shown for both E. leucoxylon and E. tricarpa. This indicates a decrease in budding with increasing temperature for E. leucoxylon and an increase in budding with increasing temperature for E. tricarpa. This is in agreement with Hudson and Keatley (2013) who derived specific temperature thresholds for budding, showing that E. tricarpa buds are significantly (and positively) 
Hudson et al., Wavelet characterisation of eucalypt flowering and the influence of climate and budding

related to higher minimum temperature $\left(\geq 9^{\circ} \mathrm{C}\right)$, and for E. leucoxylon buds are negatively related to elevated maximum temperature $\left(>23^{\circ} \mathrm{C}\right)$..

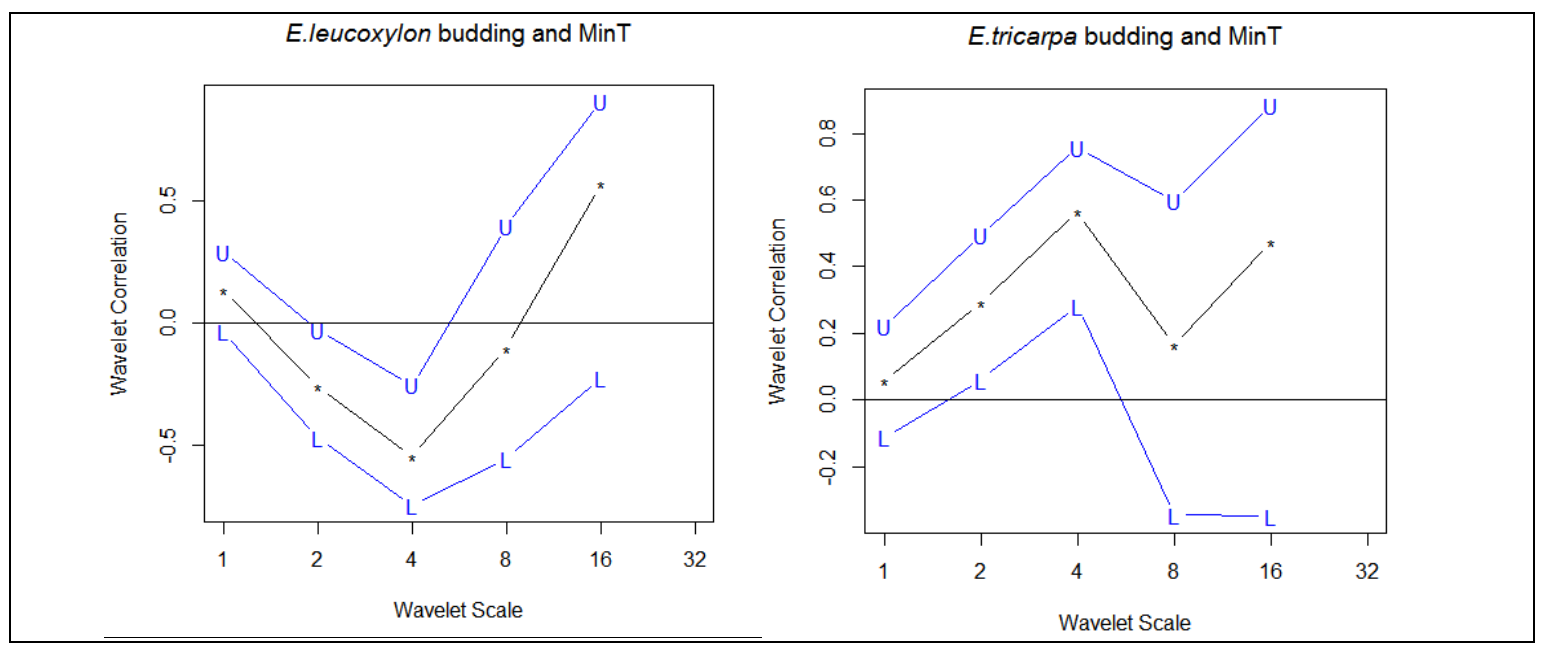

Figure 1. Wavelet correlation of flowering with MinT: E. leucoxylon and E. tricarpa.

Table 2. Wavelet (scale 3) correlation of peak budding intensity and climate variables (* signifies $\mathrm{P}<0.05$ ).

\begin{tabular}{|l|c|c|c|c|c|c|c|c|}
\hline & \multicolumn{2}{|c|}{ MeanT } & \multicolumn{2}{c|}{ MinT } & \multicolumn{2}{c|}{ MaxT } & \multicolumn{2}{c|}{ Rainfall } \\
\hline Period (months) & $\mathbf{2}$ & $\mathbf{4}$ & $\mathbf{2}$ & $\mathbf{4}$ & $\mathbf{2}$ & $\mathbf{4}$ & $\mathbf{2}$ & $\mathbf{4}$ \\
\hline Budding & & & & & & & & \\
\hline E. leucoxylon & $-0.30^{*}$ & $-0.57^{*}$ & $-0.26^{*}$ & $-0.55^{*}$ & $-0.31^{*}$ & $-0.58^{*}$ & 0.09 & 0.27 \\
\hline E. tricarpa & $0.31^{*}$ & $0.53^{*}$ & $0.29^{*}$ & $0.57^{*}$ & $0.31^{*}$ & $0.51^{*}$ & 0.09 & -0.15 \\
\hline
\end{tabular}

\subsection{Budding influences on flowering}

Budding was recorded in all months. MODWT-MRA identified four subcomponents in both the flowering and budding series - characterised as a non-flowering/budding phase, a subcomponent delineating duration, annual and intensity cycles (not reported here). An inverse relationship between flowering and budding is shown between E. leucoxylon and E. tricarpa (Figure 2 and Table 3). For E. leucoxylon flowering increases significantly with increased budding intensity at the 1 and 2 month scales (Table 3). For E. tricarpa flowering decreases significantly with increased bud intensity at 1 and 4 months (Figure 2).

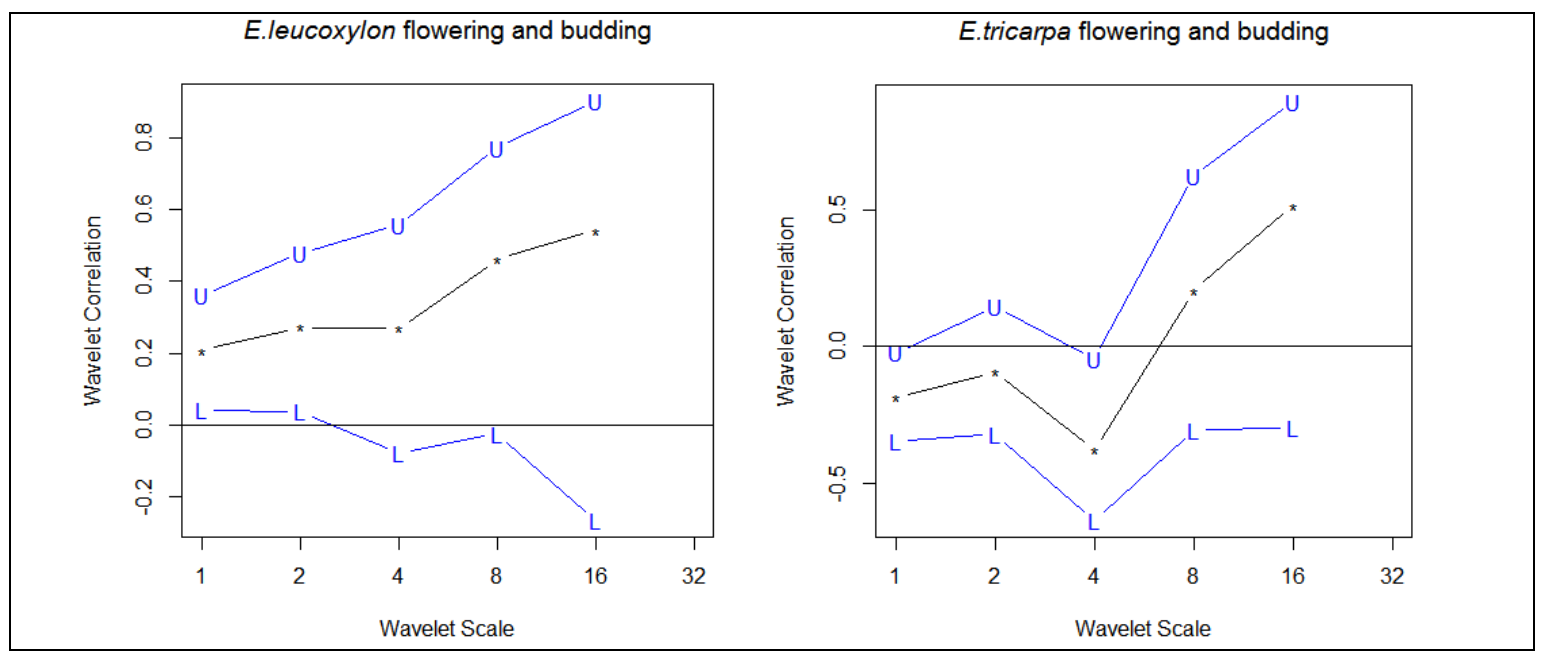

Figure 2. Wavelet correlation of flowering with budding for E. leucoxylon (LHS) and E. tricarpa (RHS). 
Hudson et al., Wavelet characterisation of eucalypt flowering and the influence of climate and budding

Table 3. Wavelet (scale 3) correlation of peak flowering intensity with peak budding (* signifies $\mathrm{P}<0.05$ ).

\begin{tabular}{|l|cccc|}
\hline \multicolumn{1}{|c|}{ Flowering } & Budding & Budding & Budding & Budding \\
\hline Period (months) & $\mathbf{1}$ & $\mathbf{2}$ & $\mathbf{4}$ & $\mathbf{8}$ \\
\hline E. leucoxylon & $0.21^{*}$ & $0.27^{*}$ & 0.27 & 0.46 \\
\hline E. tricarpa & $-0.19^{*}$ & -0.10 & $-0.38^{*}$ & 0.20 \\
\hline
\end{tabular}

\subsection{Climate influences on flowering}

From Table 4 a similar relationship between flowering and climate exists for both E. leucoxylon and E. tricarpa, this is in agreement with Hudson et al., (2011a). For E. tricarpa both temperature variants have a significant negative relationship with flowering at the 2 and 4 month scales (Table 4). Eucalyptus tricarpa was the only species for which rainfall has a significant (and positive) relationship with flowering at the 4 month scale. This indicates that cooler, wetter periods lead to greater flowering intensity for E. tricarpa. Both temperature variants at 2 and 4 months (scales) were also significant and negative for E. leucoxylon's flowering intensity.

Table 4. Wavelet (scale 3 ) correlation of peak flowering intensity and climate variables (* signifies $\mathrm{P}<0.05$ ).

\begin{tabular}{|l|l|l|l|l|l|l|l|}
\hline Flowering & \multicolumn{2}{|c|}{ MeanT } & \multicolumn{2}{c|}{ MinT } & \multicolumn{2}{c|}{ MaxT } & \multicolumn{2}{c|}{ Rainfall } \\
\hline Period (months) & $\mathbf{2}$ & $\mathbf{4}$ & $\mathbf{2}$ & $\mathbf{4}$ & $\mathbf{2}$ & $\mathbf{4}$ & $\mathbf{2}$ \\
\hline E. leucoxylon & -0.45 & $-0.45^{*}$ & $-0.48^{*}$ & $-0.63^{*}$ & $-0.42^{*}$ & $-0.56^{*}$ & -0.06 \\
\hline E. tricarpa & $-0.31^{*}$ & $-0.76^{*}$ & $-0.31^{*}$ & $-0.74^{*}$ & $-0.30^{*}$ & $-0.77^{*}$ & 0.12 \\
\hline
\end{tabular}

\subsection{Wavelet cross-correlational analyses}

Level 3 and Level 4 Wavelet cross-correlation (WCCORR) of flowering with budding: WCCORRs between peak flowering and budding intensity were lagged from 0 and 36 months prior to the species-specific peak flowering month. An illustration of these level 3 and level 4 WCCORR profiles of flowering and of budding are given in Figure 3 for E. tricarpa. Level 3 highlights the agreement in the annual production of buds and annual flowering, whereas Level 4 indicates that there is also a biennial agreement in the production of buds and flowering. Although budding was recorded in all months, the more probable months for start, end and peak budding were identified (Table 5). The level 3 WCCORRs can be viewed as the highest absolute value of the WCCORRs, for lags either in the short term ( $\leq 6$ months prior to peak flowering), or the long term ( $>6$ months $)$ (Table 5).
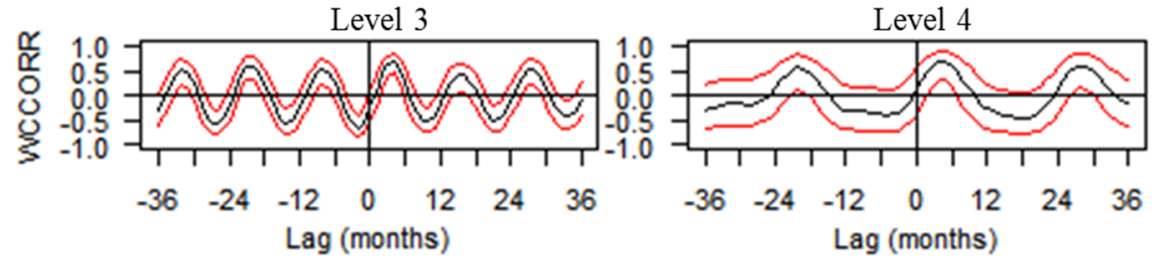

Figure 3. Levels 3 and 4 wavelet cross correlations of flowering and budding in E. tricarpa.

Table 5. Wavelet cross correlation (scale 3 ) of peak flowering and budding intensity and climate variables $(*$ signifies $\mathrm{P}<0.05)$ MinT $=$ minimum temperature 3; WCCORRs based on imputed values.

\begin{tabular}{|c|l|l|c|l|l|l|}
\hline \multicolumn{3}{|c|}{ Flowering } & \multicolumn{1}{|c|}{ Budding } & \multicolumn{1}{|c|}{ Flowering } \\
\hline Species & \multicolumn{1}{|c|}{ MinT } & \multicolumn{1}{|c|}{ Rainfall } & Species ${ }^{*}$ & \multicolumn{1}{|c|}{ MinT } & \multicolumn{1}{|c|}{ Rainfall } & \multicolumn{1}{|c|}{ Budding } \\
\hline E. leucoxylon & $0.80^{*}[-5]$ & $-0.35^{*}[-4]$ & E. leucoxylon & $-0.60^{*}[-1]$ & $0.23[-1]$ & $-0.60^{*}[-4]$ \\
Peak: Aug/Sept & April & May & Peak: May & Apr & Apr & May \\
\cline { 2 - 5 } Start: May & $-0.77^{*}[-11]$ & $0.37^{*}[-10]$ & Start: Jan & $0.56^{*}[-7]$ & $-0.26[-6]$ & $0.52^{*}[-10]$ \\
End: Dec & Oct $\Delta=6$ & Nov $\Delta=6$ & End: Dec & Oct $\Delta=6$ & Nov $\Delta=5$ & Nov $\Delta=6$ \\
\hline E. tricarpa & $-0.77^{*}[-1]$ & $0.35^{*}[-1]$ & E. tricarpa & $-0.66^{*}[-5]$ & $0.23[-3]$ & $-0.66^{*}[-2]$ \\
Peak: July & June & June & Peak: Mar & Oct & Dec & May \\
Start: Apr & $0.77^{*}[-7]$ & $-0.43^{*}[-7]$ & Start: Dec & $0.64^{*}[-11]$ & $-0.20[-10]$ & $0.54^{*}[-8]$ \\
End: Sept & Dec $\Delta=6$ & Dec $\Delta=6$ & End: Apr & Apr $\Delta=6$ & May $\Delta=7$ & Nov $\Delta=6$ \\
\hline
\end{tabular}


Level 3 WCCORRs of budding with temperature and rainfall variables: WCCORRs between budding and climate is given in Table 5 for each species. The number of months at which either lag occurs prior to peak budding intensity, differs for each species (Table 5, Figure 4). Note that E. tricarpa's short term lag of budding with minimum temperature is negative $(-0.66)$ and occurs in October, 5 months prior to peak budding. The corresponding long term lag for E. tricarpa is positive (0.64) and 11 months before its peak budding in April (Table 5, Figure 4). Similarly E. leucoxylon's short term lag of budding with minimum temperature is negative $(-0.60)$ and occurs in April, 1 month prior to peak budding, with corresponding long term lag positive $(0.56)$ at 7 months before its peak budding (October, Table 5). Budding was not significantly impacted by rainfall.

Level 3 WCCORRs of flowering with climate: WCCORRs between peak flowering intensity and the temperature variants and rainfall (Table 5) show that E. tricarpa's short term lag of flowering with minimum temperature is negative (-0.77) and occurs in June, 1 month prior to peak flowering, with corresponding long term lag for E. tricarpa, positive (0.77) occurring 7 months before its peak flowering intensity in December (Table 5, Figure 4). For the same lagged months E. tricarpa's flowering has the opposite relationship with rainfall, positive (0.35) 1 month prior to peak flowering, with corresponding long term lag negative (-0.43) at lag 7 months. The WCCORRs for E. leucoxylon's flowering with climate is opposite to that of E. tricarpa; with the short term lag of flowering with minimum temperature being positive (0.80), occurring in April, 5 months prior to peak flowering; with corresponding long term lag negative $(-0.77)$ occurring 11 months before peak flowering in October (Table 5, Figure 4). The wavelet cross-correlation profiles show that for budding and flowering there is also a maximum positive and maximum negative cross-correlation, which occur approximately 6 months apart (see Figure 4 and the delta values $(\Delta)$ in Table 5 ).
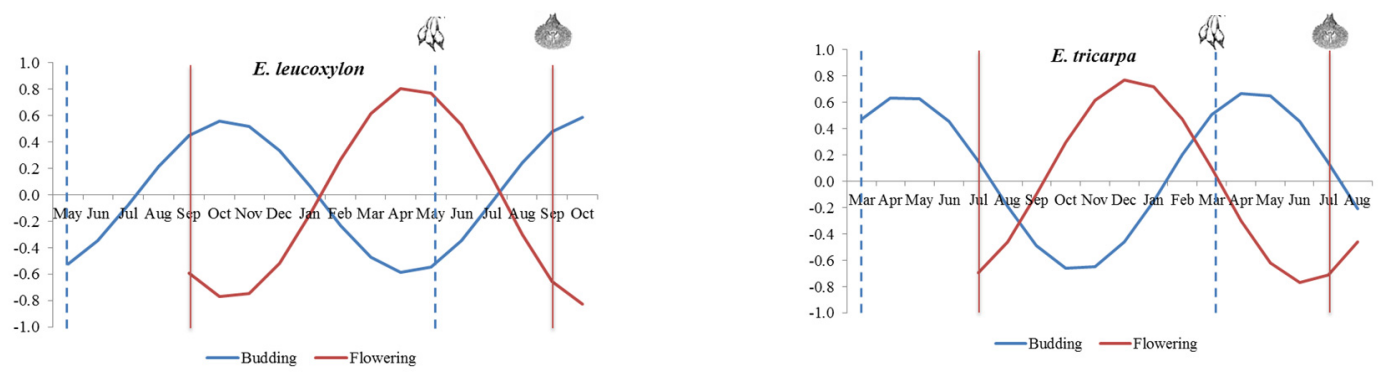

Figure 4. Cross correlations of peak budding and flowering with minimum temperatures.

\section{DISCUSSION AND CONCLUSIONS}

Temperature variants (minimum and maximum) significantly influence budding and flowering at 2 and 4 months with 4 months having a stronger influence in both species. For flowering, in both E. leucoxylon and $E$. tricarpa, this relationship is negative. In E. tricarpa maximum temperature, which usually occurs during the day, is just slightly more influential than minimum temperature. However, minimum temperature, which is usually associated with night time temperatures, has the greater influence on flowering in E. leucoxylon. Rainfall has a significant, positive relationship with flowering at the 4 month scale in E. tricarpa but the relationship for E. leucoxylon and rainfall was not significant. In budding the temperature variables at four months also have the stronger influence in both species; however, minimum temperature has the slightly greater influence in E. tricarpa and maximum temperature in E. leucoxylon. Rainfall does not have any significant influence on either species' budding. As has been found with flowering, level 3 is identifying an annual cycle (Hudson et al., 2011a) in budding. Also, the strongest correlation seems to occur at 1 or 2 months before peak flowering. This agrees with Keatley and Hudson (2012) who found that a 2 month lag aligned with the start and finish of budding and flowering as well as their intensities.

In the cross correlations between flowering and budding subcomponent, level 4 indicates a weak two year cycle in bud and flowering production. Singular spectrum analysis and wavelets methods have previously found a two year cycle in flowering in both species (Hudson and Keatley, 2010; Hudson et al., 2011a). These results indicate a 2 year cycle in bud production being carried through to a 2 year cycle in flowering intensity, which implies that enough buds have been produced to survive through to turning into flowers for a two year cycle. This has also been observed in the field for E. regnans (Ashton, 1975) and for E. viminalis (Dooley et al., 2010).

As has been noted previously, for these two species, the influence of temperature cycles throughout the year (Hudson et al., 2011a). This phenomenon has also been observed for flowering in other studies (Fitter et al., 1995; Roberts, 2010; Sparks and Carey, 1995) but to date, to our knowledge, not shown for budding, Additionally, not all monthly temperatures are equal in their influence on flowering (and budding) and not all 
months have been found to have warmed or cooled significantly (Amano et al., 2014; Keatley and Hudson, 2007). This may in part explain the differing responses observed in phenological studies. It has also been noted that the influence of temperature in the northern temperate latitudes varies with seasonality of flowering. This means that, overall, the spring flowering species are more likely to be influenced by temperatures within three months prior to flowering (Fitter et al., 1995; Roberts, 2010; Sparks and Carey, 1995; Wolkovich et al., 2014), whereas for species which commence flowering later, are more likely to be influenced by temperatures three or more months prior (Fitter et al., 1995; Roberts, 2010; Sparks and Carey, 1995). Additionally, there appears to be a cut off when this temperature influence switches from an advance in flowering to a delay. A range of 4 to 6 months prior to flowering has been indicated (Amano et al., 2014; Fitter et al., 1995) and is possibly more related to the response lag as defined by Amano et al., 2014 (i.e. the difference between the first flowering month and month most responsible for flowering time). A primary response lag is indicated in this study's results (and previous examinations) of peak eucalypt flowering and climate interactions (Hudson and Keatley, 2010; Hudson et al., 2011a) and budding. These species which both commence flowering in Autumn have different lags. In E. leucoxylon the strongest correlation occurs at 5 months and is positive indicating a delay in flowering, whereas E. tricarpa has a negative and short response lag of one month indicating earlier flowering from a warming climate. These responses are in line with the range indicated above. It seems that flowering in temperate species which have a small lag (i.e. influenced by temperatures within 2 months) respond to changes in temperature better (Amano et al., 2014; Wolkovich et al., 2014) - hence flowering in $E$. tricarpa should be more responsive to a changing climate than E. leucoxylon. However, in some climates rainfall is also a significant influence (Keatley and Hudson, 2007; Prieto et al., 2008). In both species rainfall has the opposite influence to temperature on flowering which implies some mitigation of the temperature influence. Additionally, flowering is only part of the reproductive cycle and its timing is influenced by budding (Hudson and Keatley, 2013; Keatley and Hudson, 1998; Primack, 1987). In the case of E. leucoxylon the influence of temperature (and rainfall, however, it is not significant) on budding is the opposite, but not quite as strong, to that of flowering. Additionally, the response lag of budding is also shorter by 4 months than that of flowering. This shorter lag of one month implies that budding in this species should be more able to respond a changing climate than $E$. tricarpa which has a response lag of 5 months. However, it seems that the influence of temperature (and rainfall) in budding underpins that of flowering in E. tricarpa.

Overall, the wavelet (cross) correlations reflect the relationship of bud development and flowering in both species at this site. The positive relationship in E. leucoxylon illustrates that buds develop over time and continue to do so once flowering commences. Flowering occurs alongside bud development but the majority of flowers are produced later in the flowering period. This is supported by the flowering pattern being negatively skewed in E. leucoxylon (Keatley et al., 2004). Overall E. tricarpa buds develop prior to flowering and then once the buds are mature flowering occurs. The positively skewed flowering pattern in $E$. tricarpa indicates that the majority of flowers are produced earlier in the flowering period (Keatley et al., 2004).

\section{ACKNOWLEDGMENTS}

We thank The Dahl Trust for their support in the digitizing of the budding data.

\section{REFERENCES}

Amano, T., R.P. Freckleton, S. Queenborough, S.W. Doxford, R.J. Smithers, T.H. Sparks, and W.J. Sutherland (2014). Links between plant species' spatial and temporal responses to a warming climate. Proceedings of the Royal Society of London B, 281. doi: 20133017

Ashton, D.H. (1975). Studies of flowering behaviour in Eucalyptus regnans F. Muell., Australian Journal of Botany, 23, 399-411.

Dooley, G.M., M.D. Murray, M.T. Lutze, G.J. McCarthy, P.C. Perry, and P.C. Fagg (2010). Seedcrop development in Eucalyptus viminalis in HEMS forest of East Gippsland. Austalian Forestry, 73(1).

Fitter, A.H., R.S.R. Fitter, I.T.B. Harris, and M.H. Williamson (1995). Relationships between first flowering date and temperature in the flora of a locality of central England. Functional Ecology, 9, 55-60.

Gencay, R., F. Selcuk, and B. Whitcher. (2001). An Introduction to Wavelets and Other Filtering Methods in Finance and Economics. Academic Press, San Diego.

Hudson, I.L., and M.R. Keatley. (2010). Singular spectrum analysis: climatic niche identification. In Hudson, I.L. and Keatley, M.R. (eds), Phenological Research: Methods for environmental and climate change analysis (pp. 393-424). Springer, Dordrecht. 
Hudson, I.L., and M.R. Keatley. (2013). Scoping the budding and climate impacts on Eucalypt flowering: nonlinear time series decomposition modelling. In Piantadosi, J., Anderssen, R.S. and Boland J. (eds) MODSIM 2013. 20 $0^{\text {th }}$ International Congress on Modelling and Simulation Society of Australia and New Zealand. Dec 1-6, 2013.

Hudson, I.L., M.R. Keatley, and I. Kang (2011a). Wavelet characterization of eucalypt flowering and the influence of climate. Environmental and Ecological Statistics, 18(3), 513-533.

Hudson, I.L., S.W. Kim, and M.R. Keatley. (2010). Climatic influences on the flowering phenology of four Eucalypts: a GAMLSS approach. In Hudson, I.L. and Keatley, M.R. (eds), Phenological Research: Methods for environmental and climate change analysis (pp. 209-228). Springer, Dordrecht.

Hudson, I.L., S.W. Kim, and M.R. Keatley. (2011b). Climate effects and temperature thresholds for Eucalypt flowering: a GAMLSS ZIP approach. Paper presented at MODSIM2011, 19th International Congress on Modelling and Simulation. Modelling and Simulation Society of Australia and New Zealand, Dec 12-16.

Keatley, M.R., and I.L. Hudson (1998). The influence of fruit and bud volumes on Eucalypt flowering: An exploratory analysis. Australian Journal of Botany, 46(2), 281-304.

Keatley, M.R., and I.L. Hudson. (2007). Shift in flowering dates of Australian plants related to climate: 19832006. Paper presented at MODSIM 2007 International Congress on Modelling and Simulation. Land, Water and Environmental Management: Integrated Systems for Sustainability Modelling and Simulation Society of Australia and New Zealand, Dec 10-13.

Keatley, M.R., and I.L. Hudson. (2012). The influence of budding on the flowering of four eucalypt species. Paper presented at Phenology 2012: Climate change impacts and adaptations, Sept 10th - 13th.

Keatley, M.R., I.L. Hudson, and T.D. Fletcher (2004). Long-term flowering synchrony of Box-Ironbark eucalypts. Australian Journal of Botany, 52(1), 47-54.

Law, B., L. Mackowski, and T. Tweedie (2000). Flowering phenology of myrtaceous trees and their relation to climate, environmental and disturbance variables in northern New South Wales. Austral Ecology, 25, $160-178$

Murray, M.D., and M.T. Lutze. (2004). Seedcrop development in Eucalyptus obliqua and Eucalyptus cypellocarpa in High elevation Mixed Species forests of East Gippsland (Research Report 387). Orbost: Forest Science Centre.

Percival, D., and A. Walden. (2000). Wavelet Methods for Time Series Analysis. Cambridge University Press, Cambridge, UK.

Porter, J.W. (1978). Relationships between flowering and honey production of Red Ironbark, Eucalyptus sideroxylon (A. Cunn.) Benth., and climate in the Bendigo district of Victoria., Australian Journal of Agricultural Research, 29, 815-829.

Post, E., C. Pedersen, C.C. Wilmers, and M.C. Forchhammer (2008). Phenological sequences reveal aggregate life history response to climatic warming. Ecology, 89(2), 363-370.

Prieto, P., J. Peñuelas, R. Ogaya, and M. Estiarte (2008). Precipitation-dependent Flowering of Globularia alypum and Erica multiflora in Mediterranean Shrubland Under Experimental Drought and Warming, and its Inter-annual Variability. Annals of Botany, 102, 275-285. doi: 10.1093/aob/mcn090

Primack, R.B. (1987). Relationship among flowers, fruits and seeds. Annual Review of Ecology and Systematics, 18, 409-430.

Roberts, A.M.I. (2010). Smoothing methods. In Hudson, I.L. and Keatley, M.R. (eds), Phenological Research: Methods for environmental and climate change analysis (pp. 255-269). Springer, Dordrecht.

Semple, W.S., and T.B. Koen (2010). Reproductive Phenology of White Box (Eucalyptus albens Benth.) in the Southern Portion of its Range: 1997 to 2007. Proceedings of the Linnean Society of New South Wales, $131,93-110$.

Sparks, T.H., and P.D. Carey (1995). The responses of species to climate over two centuries: An analysis of the Marshman phenological record, 1736-1947. Journal of Ecology, 83, 321-329.

Su, Y., A. Gelman, J. Hill, and M. Yajima (2011). Multiple Imputation with Diagnostics (mi) in R: Opening Windows into the Black Box. Journal of Statistical Software, 45(2), 1-31.

Whitcher, B.J., P. Guttorp, and D.B. Percival (2000). Wavelet Analysis of Covariance with Application to Atmospheric Time Series. Journal of Geophysical Research, 105(D11), 941-962.

Wolkovich, E.M., B.I. Cook, and T.J. Davies (2014). Progress towards an interdisciplinary science of plant phenology: building predictions across space, time and species diversity. New Phytologist, 201, 1156-1162. 